\title{
The Social Construction of the Role of Consultants Agency in the Village of Communication Strategy of Development
}

\author{
$1^{\mathrm{st} *}$ Dwinarko \\ Faculty of Communication \\ Universitas Bhayangkara of Jakarta \\ Raya \\ Jakarta, Indonesia \\ dwinarko@dsn.ubharajaya.ac.id
}

\author{
$2^{\text {nd }}$ Otong Yuda \\ Chairman of $F K-B P D$ \\ BPD \\ Subang, Indonesia \\ yudhapadjadjaran@gmail.com
}

\author{
$3^{\text {rd }}$ Ahamad Sihabudin \\ Faculty of Communication of \\ Universitas Untirta \\ Banten, Indonesia \\ sihab@untirta.ac.id
}

\begin{abstract}
This aims of the study to understand the role of the Village of Consultative Body (BPD) in the involvement of planning and supervision through a process of community to aspirations from the bottom up. The theory used is a social construction with qualitative methods, constructivist paradigms in the postmodern of view. The results of the study show that development is fair and equitable by implementing to development of planning that is connected from the village to the central government, and synergistic control mechanisms, through a collaborative model of village community institutions, law enforcement and the central government based on credibility, accountability, and transparency. The analysis was carried out using literature studies, case studies on the application of fund allocations and village maps, by conducting observations and in-depth interviews in the six villages in Serangpanjang Sub-district, of Subang District. The research of findings that collaborative planning of model from below and increased that recruitment of village community institutions that understand to management and legal knowledge is supported by the active community to participation with supervisory management of training with technical capabilities for development oversight and connected with the central government through by technology. Mapping of the village to development (road maps) in terms of infrastructure, human resources and natural resources that are connected to the internet and networking of each village, so that the control mechanism and the need for transparency in the use of the budgeting. The road map must be viewable online regarding the allocation and location of the development of applied.
\end{abstract}

Keywords- Social Construction, Strategy, Development Communication

\section{INTRODUCTION}

The role of the Village Consultative of Body, abbreviated as BPD, is one of the villages of community institutions, has been legal to listed in Law of number 6 of 2014 concerning to Villages, and Regulation of the Minister of Home Affairs of number 110 of 2016 concerning BPD, is a strategic effort in the communication of development through the community of involvement through deliberations and membership is chosen through a democratic of the process. BPD is an institution that carries out a government of functions whose members are representatives of the villagers based on regional to representation and are democratically of the determined. The Village of Deliberation is a form of the BPD, and elements of the community organized by the Village Consultative Body to agree on the strategic matters.

According to Berger and Luckmann [1] it is stated that society as an objective of reality and society as a Subjective. Village development is objectively an effort of the government in the act of equitable development, both infrastructure and the economy by providing a significant budget of the village, with an allocation of almost one billion per village, according to geographical location and population as a reference for the revenue. Utilization of the budget Village funds has a subjective meaning, depending on the organization and the people who run and are involved in the planning, implementation, monitoring and beneficiary process of development outcomes. According to the explanation of Chapter II, article 2 paragraph 4 point 1, the [2] states that the existence of the Subang District of Serangpanjang Sub-district is an expansion of the Sagalaherang District by coordinating to six villages, namely of the Village are Cijengkol, Talagasari, Cintamekar, Ponggang, Cikujang, and Cipancar.

The objectivity of the role of the BPD encountered many obstacles that must be faced, this is due to many factors, including of community knowledge about BPD is still lacking; human resources that have not been able to meet the criteria of being a member of the BPD; operational to funds that are still minimal; the lack of public awareness about supervision of village to development; and there is an element of intent that is not socialized about the role of BPD to the community.

Referring to article 31 of Regulation of the Minister of Home Affairs of Number 110 of 2016 concerning BPD, It has functions including discussing and agreeing on a Village Regulation Draft with the Village Head; accommodate and channel the aspirations of the village community, and supervise the performance of the Village Head.

Furthermore, Article 32 explains that the duties of BPD are: digging; accommodate; manage; and channeling people's aspirations; holding BPD and Village meetings; formed a village head election committee; holding a special village meeting for the election of the Village Head intermittently; discuss and agree on the draft Village Regulation with the Village Head; supervise the performance of the Village Head; evaluating reports on the implementation of Village Governance; creating harmonious working relationships with 
the Village Government and other Village institutions; and carry out other tasks stipulated in the provisions of the legislation.

The process of selecting and forming a democratic member of the BPD is still not understood by the village community and is often manipulated by groups that support the village head, so people who occupy BPD members refer to people who are easily controlled by the village head.

The position of the BPD in Telagasari Village is very intimidated and criminalized by village officials, such as the management of the organizational structure intervened by a village secretary and his group which requires that the chair of the BPD be replaced regularly every year; operational revenue that is not in accordance with the planned budget use; not included in development to meetings at the sub-district level. (Interview via WA with BPD Chair Echy 03/14/2020).

The democratic process for the election of BPD in Ponggang Village at the end of 2017 which was stalled in the inauguration, up to 4 months after the election was carried out because of the elements who did not want elected BPD members.

Knowledge about the process of selecting BPD members in the view of one of the community leaders who are members of the Regional People's Representative Council (DPRD) does not need to be done democratically and does not know the role and function of the BPD in village laws and ministerial regulations.

The role and function of the BPD are still not well understood in the community or in the village administration in community empowerment and village development. In article 1 paragraph 9, village regulation number 11 of 2019 explains the Village Government, namely as the administration of government affairs and the interests of the local community in the system of government of the Unitary Republic of Indonesia.

Furthermore, in paragraph 10, article 1, the candy explains that Village Development is an effort to improve the quality of life and life for the maximum welfare of the village community. Whereas in article 1 paragraph 11 of the regulation of the village minister stated that, Empowerment of the Village Community as an effort to develop independence and welfare of the community by increasing knowledge, attitudes, skills, behavior, abilities, awareness, and utilizing resources through the determination of policies, programs, activities, and assistance in accordance with the essence of the problem and the priority needs of the village community.

BPD activities are very challenging, when BPD Ponggang tries to move their functions and roles actively, the term performance of BPD appears over, this is done by a number of leaders in the sub-district and in the village. In addition, the issue of receiving operational allowances received by the BPD means that the BPD is enjoying village funds that are not halal. Even though the operational allowances for the new BPD are in accordance with the permanent producer of the village head and village apparatus whose amounts are $7.5 \%$ to $10 \%$, and the conditions are varied.

BPD as a partner of the village head in his observations is often interpreted as an enemy of the village head when compiling the village budget and supervising village development and this is not in line with the concept of a village development communication strategy.

According to Servaes (2002) in [3] explains that communication development as knowledge, which aims to reach consensus to calculate the interests, needs and capacities of all those concerned. Development communication is the deliberate and strategic use through interpersonal, participatory and mediated channels in supporting positive change between individuals and communities at the micro and national level at a macro level[4].

According to Berger [1] explains that, the dialectical phenomenon of society in the sense that society is a human product, which continuously acts back to the producer.

Society is a human product. There is no other being except that which is given to him by human activity and consciousness. There is no social reality separate from humans. Each individual biography is an episode in the history of society, which precedes and survives. The community was there before the individual was born, and it will be there after he dies. Society as a result of social processes, from individuals to individuals. Someone holds on to identity, in carrying out various projects that shape his life. Humans cannot exist apart from society. Two statements, that society is a product of humans and that humans are products of society, are not in conflict. They better reflect the dialectical character inherent from the phenomenon of society.

Referring to the explanation, it can be understood that, society is a human product that is carried out with ongoing socialization. Socialization means that development communication can emphasize understanding of human activity through interpersonal, participation, transparency, and awareness, by using media information tools actively, by focusing on different needs, and considering various problems in society.

Human products can be in the form of acceptance of criticism and input to improve the quality and quantity of development through synergistic cooperation, which is complete and supports human resources through community understanding in an effort to improve people's lives in general.

Village communities as villagers are seen as the lower strata of society. According to Barry and John (2003: 286) explain that facts at the bottom level, which is called a rough fact, can exist independently of humans and their institutions. The facts at the top level, which are stated as institutional facts, depend on human institutions and especially on the related collective intentionality.

Based on this explanation, the social construction of village development as stipulated in the law clearly requires the role of community participation so that village development can be equitable, and obtain prosperity and fair use of the Village Fund budget is achieved.

Social construction is a step in the communication strategy as an act of the community, in the form of socializing activities of shared values and norms. Kirk, et al (2007) state that strategic communication is different from integrated communication because the focus is on how an organization communicates through organizational efforts [5]. The emphasis is on the strategic application of communication and how an organization functions as a social actor to advance its 
mission. The purpose of strategic communication is very important. Whereas academic research on organizational communication broadly examines the various processes involved in how people interact with inflexible organizations (including inter-group, group, and network communication), strategic communication focuses on how the organization itself presents and promotes itself through intention. National activities of leaders, employees and communication practitioners. Of course, this does not exclude their use of building relationships or networks in strategic processes.

Socialization is a human product in an effort to actively participate in determining the quality of development supported by human and natural resources. By understanding the participation of each individual synergistically and integrated as part of the community's individual goals, the community, the nation and the state can achieve equitable development.

According to Disca that formal socialization can be carried out by all officially recognized institutions, organizations, agencies, groups that determine the appropriate goals, rules, duties, privileges and obligations [6]. It was further explained that Informal socialization was a process of assimilating attitudes, values, patterns of behavior obtained in personal life. Informal socialization agents are family, friends (group), colleagues, etc. According to some researchers [6], informal socialization can and must be carried out even by professional corps, outside the classroom. Therefore they need supporting activities outside the curriculum or, more precisely, educational activities carried out under the informal curriculum. In Karkoulian, Silva, Nasr, Linda, (2008: 16) quoted by Disca [6].

According to Keyton, (2011) in Fred C (2010: 1) Communication can be defined as the process of sending information and mutual understanding from one person to another. The word communication comes from the Latin word, communist, which means general. This definition underlines the fact that if there is no shared understanding resulting from the exchange of information, there is no communication.

Furthermore, Eisenberg, (2010) in Fred C (2010: 4) that an effective and good communication process is needed to overcome the obstacles faced, among others as follows: senders of messages afraid of being criticized; Language coding is often understood differently; a letter that is used as a tool/medium to vent staff anger; decoding is interpreted as a barrier to the distance between the message giver and receiver of the message; and feedback on understanding that is not as expected.

Many terms are used in describing the development, as according to Matowanyka, (1991) in Fred C (2010: 4) stated that development is often confused with economic growth measured only in terms of annual increases in per-capita income or gross national product, regardless from the distribution and level of community participation in effective growth (Mahmoud, 1991). Furthermore Seers (1972) asserts that development means the conditions for the realization of human personality. Therefore the evaluation must consider three criteria related to the reduction in poverty, unemployment, and inequality.
According to Edwards (1993) in Isaac (2018: 3) that to understands the term, development as, much about the enrichment of the lives of all people in society (p.80). Odaro (1994) also defines development not merely as an economic phenomenon but rather multi-dimensional. The process of that involves the reorganization and reorientation of the whole economic and social system. This scientific view of development offers a relative understanding of the meaning of development. Thus, development can be defined as the process of increasing the standard of living of a group of people.

Communication, on the other hand, is defined as, the process or act of transmitting messages from the sender to the receiver through the channel and with noise interference (DeVito, 1986, p. 61). Whereas Lunenburg (2010) also considers communication as a process of transmitting information and understanding together from one person to another. Based on the definition of communication above, it can be concluded that communication is the process of sharing information with the aim of achieving understanding between two people, or between people. (In Isaac Bisilki, 2018: 4).

Isaac (2018: 4) said the term can further be defined as a process whereby information is shared between two people or between a group of people, either face-to-face or through the media with the naming given by the recipient. After exploring the definition of development and communication from both scholars' views, and by concluding my own definition, as indicated above, the subject of development communication became the focus

United Nations (UN) in Bisilki. (2018: 4) on the other hand, it offers a broader definition of communication for development. The United Nations defines it as a process that enables people to speak, express their aspirations and concerns, and participate in decisions relating to development (General Assembly Resolution 5/172, article 6). It offers explanations that go beyond the traditional understanding of communication that emphasizes concepts such as dissemination, information, messages, media and persuasion. Development communication can be understood as participatory communication activities that focus on the needs of people at various levels, taking into account their concerns, acceptance and input to achieve complete cooperation and support for efforts aimed at improving their lives.

United Nations Educational, Scientific and Cultural Organization (UNESCO) in Bisilki. (2018: 8) explain that participatory communication is a social process in which groups with shared interests build together messages that are oriented towards improving their existential situation and changing social structures that are unjust (Mody 1991). Participatory communication does not exist, at the heart of this concept, is the need for information exchange to contribute to solving development problems and improving the quality of life of certain target groups, such as well as to implementing needs analysis and evaluation mechanisms in the communication process (Bessette 1996).

According to Dror Etzion. (2007: 653-654) explains that Organizational Environmental Construction. As predicted by neo-institutional theory, structures and processes that companies develop for compliance purposes are made to protect the organization from the pressures of the 
organizational environment (J. Maxwell et al., 1997; Ramus \& Montiel, 2005).

According to Daniel Lerner (1958) in Inagaki (2007: 5) that, traditional society symbolizes a modernization approach in communication, which states that mass media exposure enables people to develop a sense of empathy, the ability to imagine and accept new ideas outside of local conditions someone and tradition.

This model prioritizes top-down, one-way dissemination of modern ideas through mass media channels and is based on the idea that mass media messages have a direct impact on the attitudes and behavior of recipients (Servaes 1991 in Inagaki, 2007: 5).

According to Inagaki (2007: 6) that, Mass media campaigns in a number of development initiatives until 1970 were more or less built on the presumption of the modernization paradigm. In addition, the modernization paradigm is consistent with some of the most popular contemporary communication approaches in media campaigns, such as social marketing and educationentertainment, which use mass media as the main channel for sending persuasive messages made by development specialists to the target population.

Inagaki (2007) the emphasis of the modernization paradigm on the model of communication information transmission is systematically adopted in the influential diffusion theory of Everett Rogers' influential innovation $(1962,1983)$, which has been used for decades as a popular theoretical basis for communication development initiatives [7]. In Roger's words, the diffusion of innovation is the process by which (1) an innovation (2) is communicated through certain channels (3) over time (4) among members of the social system (1983). His theory has been criticized in many fields but mainly because it ignores the importance of interpersonal communication in the diffusion process. However, the latest version of this theory incorporates this criticism and outlines the role played by various types of communication channels: mass media channels are more effective in creating knowledge about innovation, while interpersonal channels are more effective in forming and changing attitudes towards new ideas, and thus in influence the decision to adopt or reject a new idea.

Furthermore, Inagaki (2007: 12) adopted the following four categories proposed by the level of participation among these studies: (1) participation in decision making, (2) participation in implementation, (3) participation in evaluation, and (4) participation in receiving benefits[7].

Inagaki (2007) Specialists and contemporary development communication organizations are presented with many approaches and communication techniques that they can adapt to achieve specific program goals [7]. Some of the most widely used communication strategies include entertainmenteducation; social marketing; peer education; interpersonal communication involving peers, marriage partners, and service providers; group communication; community action; media advocacy; and listen to local wisdom. Most of these methods are not only based on theory alone but also have something in common with the three main theoretical traditions in development communication just discussed.
Inagaki (2007) each strategy thus operates in a fairly tightly defined set of communication channels and spaces. The objectives of communication interventions also vary between different strategies according to the conceptual premise of the underlying theoretical tradition[7].

Berger and Luckmann [8] explain that processes in which knowledge can be determined socially as reality. That the sociology of knowledge must concern itself with whatever is considered knowledge in society, regardless of the validity or invalidity (with any criteria) of that knowledge. And all human knowledge is developed, transmitted, and preserved in social situations, the sociology of knowledge must try to understand the processes carried out in such a way that the reality that is taken for granted is considered congestion. In other words, the sociology of knowledge is related to the analysis of the social construction of reality.

Berger and Luckmann (1991: 13) define reality as quality in accordance with the phenomena that we recognize that have the independence of our own volition, and to define knowledge is as a certainty that phenomena are real and they have special characteristics. In the understanding (which is recognized simply) that the terms have relevance both to ordinary people and to philosophers.

Berger and Luckmann (1991: 34) If we want to illustrate the reality of common sense, we must refer to interpretations, just as we must take into account the characters who are already familiar - but we do so in phenomenological brackets. Consciousness is always intentional; always intend or directed to the object. We can never grasp some of the substratum of consciousness that is thought to be so, only awareness of something or other. This is very independent of whether the object of consciousness is experienced as belonging to the external physical world or captured as an element of the subjective reality.

\section{METHODOLOGY}

Social construction explains the results of observations, the direct involvement of researchers for two years, and analyzes the results of direct interviews from BPD members and villagers in completing data and analysis. The time of the study began from January 2020 to June 2020 in the Serangpanjang sub-district of the Subang District.

Postmodern identity Foucault and several other thinkers claim that identity is built by social institutions and regulations (Elliot 139). Before the postmodern era, many group behaviors, individual relationships with each other, market conditions, individual-state relations, communication styles and expressions were considered more stable and long-term while they are now far from stable in the postmodern era. But totalitarian methods of constructing identity by social structures and institutions are still available and they are being developed in more complex ways. Foucault has made influential work on self-regulation, identity, and subjective experience as the main strategies of social control of modernity; and theories about the effects of new social change, variously referred to as postmodernity, final modernity, advanced capitalism, detrationalization and individualization, liquid modernity, neoliberalism, and globalization, on subjectivity, self, and identity. Elliot quotes that Marx, Durkheim, Weber, and Simmel, have analyzed the influence of the main structure of modern society on the 
subjective experience and individual self (Elliot 139). Analyze the impact of structures formed by postmodern societies and cultures that focus on certain subcultures and groups and understand individuals interested in multiple cultures in an era of unlimited identity and choice [10].

According to David Lyon, in Baldil (2016: 83) that postmodern social conditions, these new media messages provide a frame for organizing experiences, giving a sense of reality (while also blurring the line between the real and the picture). Identity, both personal identity and social identity must not be considered stable or lasting, because, conditions, insights and characteristics can change and this can cause changes in self-perception and identity in the course of time. So the condition and self-change according to the factors mentioned. The decline in the influence of conventional and religious lifestyles and the moral principles of society leads to obtaining new morality from other resources such as a new lifestyle that is more fragmented than the philosophical, scientific or recreational-based community. Fragmented lifestyles force themselves and identities to be adrift in terms of the senses. One reason may be the disappearance of conventional lifestyles from urban areas and the emergence of only lifestyles that can be reproduced by a person or group in a very short time, and this process of reproduction is as a cultural industry. (Baldil: 2016: 84)

Deakin (2005) in Baldil (2016: 84) explains that postmodernism can provide a general profile of postmodern self-identity, namely: Truth is relative; Consumerism; Selftransformation; Fragmentation of social life; Choice is unrelenting; Globalization; The Impact of Information Communication Technology on social life; People build themselves and design each other's identity. Mardin in Baldil (2016: 85) states that individuals and postmodern identities are influenced by fragmented social structures, along with postmodern times, communities, language groups, sexual groups, physician groups and fiction are preferred over national identities as references in the definition of identity.

\section{RESULTS AND DISCUSSION}

\section{A. The Social Construction of BPD}

Achieving the value of democracy in supervision, a model and pattern of social interaction in integrated development communication is needed in the knowledge of BPD members and the government regarding the provisions rather than the content of the village law not yet maximally to the community so that individual participation on the role of BPD and the community has not been carried out maximally in the development communication process.

The active role of the BPD requires budget and salary standards in accordance with the provisions of the applicable law so that there is no discriminatory treatment and can carry out its function as a community institution in the village in accordance with the expectations given.

BPD participation is a very important part of social construction as part of a development communication strategy, which is conceptualized in detail, as a bottom-up planning process in determining the basic steps of development.

Treat the government discriminatively against the role of the BPD in the form of operational benefits and performance fees that do not meet decent aspects of life and have an unprofessional impact in carrying out the tasks assigned according to the law. In this study, researchers describe the role of BPD as shown below:

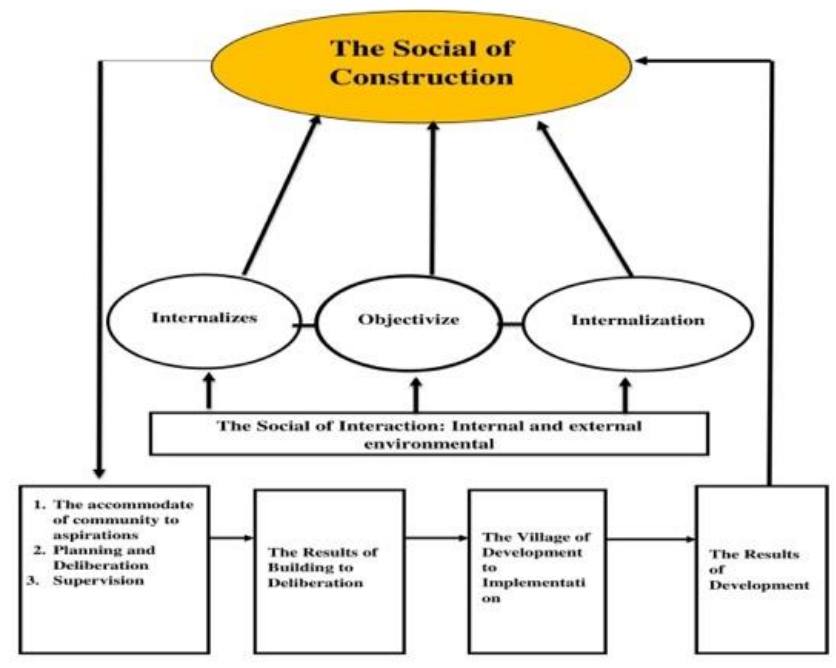

Fig. 1. The Social Construction

The social construction of the role of the BPD is the result of a democratic process and political communication formed by the government and the DPR RI. Thus the construction gives meaning together and its existence is recognized as a village community organization that is bound by Law number 6 on Villages in 2014

\section{B. The Function of BPD}

According to article 1, paragraph 4, the Law stated that, BPD or so-called institutions that carry out the functions of government and its members are representatives of the villagers based on regional representation and democratically determined.

Furthermore, in article 1 paragraph 5 it is stated that the Village Deliberation or the so-called deliberation between the BPD, the Village Government, and elements of the community organized by the BPD to agree on strategic matters.

While in article 1 paragraph 7 it is explained that the Village Regulation is a statutory regulation determined by the Village Head after being discussed and agreed with the Village Consultative Body.

According to Ridwan in Wartakini (Friday 5 May 2017) it was explained that to increase the role of the Village Consultative Body in Subang Regency, eventually formed the Village Consultative Body Communication Forum (FK BPD).

While Tatang's take of the opinion was quoted by Ridwan (5 May 2017) the formation of the forum was followed by representatives of BPD chairmen from 27 sub-districts in Subang Regency. The establishment of Subang District FKBPD can be successful must be based on sincere intentions, superior organizations, qualified knowledge, funds and willingness to sacrifice. The presence of the BPD communication forum should not clash with the village head's forum or become a rival, and must be part of efforts to advance development in the village. 
Furthermore Tatang explained that, if there are problems in BPD, it is hoped that they can be discussed in the forum as soon as possible, and find a solution. In addition, with the addition of funds in the village, there should be no additional problems, the BPD forum is expected to be able to help in finding a formulation in solving the existing problems. The establishment of Subang FK-BPD was able to run smoothly and after that immediately took part and became part of the attention in the dispense program.

\section{Recommendations for Repair of the Rule}

The Village of Consultative Body Communication Forum (FK-BPD) of Subang Regency held an audience with the Subang of DPRD Building, Road of Dewi Sartika of Subang, $(01 / 29 / 2020)$. The hearing was received directly by Deputy Speaker of the Subang DPRD, Elita Chair of Commission I from the Golkar Faction Irmayana, and Subang Head of SubDistrict Office Nana. Also attended by a number of members of the Subang DPRD, along with dozens of FK BPD Subang management.

According to Andika in Lampusatu.Com. (29-01-2020) quoting the opinion of the Chairman of the Subang of FK BPD of stated that, the initial hearing with the Subang DPRD conveyed at least three recommendations. First, conveying to the Subang of DPRD related to Regional Regulation of number 18 of 2016 which specifically BPD has no correlation with the current situation. Village Government Regulation now is the era of Law number 6 of 2014. For this reason, we ask the Subang of DPRD to revise or make a special regulation related to BPD.

Second is related to the need to include the BPD forum in each draft local government regulation that discusses the village. BPD is the lowest level aspiration institution that is in contact with the community, of course, understand the problems and conditions needed in the village, therefore the BPD Forum asks the DPRD to take part in the formulation of regulations on villages.

Third, DPRD is expected to increase operational allowances for BPD. Because the burden of supervision as one of the functions of the BPD is getting bigger. More and more with the flow of Village Funds, ADD and other programs that now many do not know which programs come directly to the village.

Meanwhile, Chair of Commission I of the Golkar of Faction Irmayana appreciated once the arrival of FK BPD Subang who conveyed his aspirations directly to the Subang DPRD, and will follow up on aspirations or recommendations to the leadership meeting related to the revised Regional Regulations and others. The same thing was expressed by Deputy Chairman of Subang DPRD, Elita promised to follow up related to the aspirations that the Subang BPD forum conveyed, and promised to involve in the formulation of regulations related to the Village.

The role of the BPD to this day is still only as an ideal discourse concept, which is a concept of development from the bottom up, but in reality there is still very little knowledge and understanding of it.

The concept of village laws that are constructed based on the democratic process is ignored by politicians to touch and discuss the role of FK-BPD even though it is a product of the democratic system that they have been working.

The results of research through intense observation over three years with different village heads, the results of development in the Sub-district of Serangpanjang, there is no significant development movement, especially infrastructure development.

Development is carried out only as a routine of the village of head and government as a venue for village development projects from the Village of Fund, Provincial of Assistance, District of Assistance, public works of assistance, aspirational of funds and so on.

\section{CONCLUSION}

BPD is part of the social construction described in the village law, and regulation of the minister of the interior is as one of the development communication strategies that must be understood in an integrated and implemented in a planned and programmed manner supported by human resources who have education, integrity, credibility, and accountability for community development goals.

Village development requires an understanding of supervision on an optimal basis through the role of the BPD which is carried out in accordance with the values and norms imposed in the Unitary State of the Republic of Indonesia and is supported by a certification of competent to the supervision of the Village of Fund so that it can benefit the quality and quantity of values of development for the society.

The BPD communication of forum is part of a strategy for inter-village for coordination in exchanging to information on the village of development for supervision and the ability to assess the quality of development outcomes of the village government.

The role of the FK-BPD can contribute maximally supported by a proper to operational of budget, with adequate and humane wage income, and does not discriminate, thus motivating to activities in order to carry out the supervisory of function.

\section{REFERENCES}

[1] B. and Luckmann., The Social Construction Of Reality. Penguin Books.

[2] "Subang of Regency to Regional of Regulation, Number 3 of 2007 concerning of the Division and establishment of Subdistrict working areas within the Subang Regency of government to environment," no. 3 , p. $2007,2007$.

[3] I. Bisilki, "Development Communication." . University of Cape Coast Department of Communication Studies Term Paper, p. 20, 2018.

[4] A. Sulistyanto, "Social Media and Moral Movement: A Critique of Jürgen Habermas' Communicative ActionsTheory," KnE Soc. Sci., vol. 2, no. 4, pp. 127-134, 2017, doi: 10.18502/kss.v2i4.878.

[5] B. A. Conway, K. Kenski, and D. Wang, "The Rise of Twitter in the Political Campaign: Searching for Intermedia Agenda-Setting Effects in the Presidential Primary," J. Comput. Commun., vol. 20, no. 4, pp. 363-380, 2015, doi: 10.1111/jcc4.12124.

[6] D. T. Crisogen, "Disca Tiberiu Crisogen. 2015. Types of Socialization and Their Importance in Understanding the Phenomena of Socialization.," Eur. J. Soc. Sci., p. 2015, 2015.

[7] N. Inagaki, "Communicating the Impact of Communication for Development. . World Bank Working Paper No. 120 Laws and Regulations :," Recent Trends in Empirical Research, no. 120. Recent Trends in Empirical Research. World Bank Working Paper No. 120 Laws and Regulations, pp. 20-34, 2007. 
[8] Peter L. Berger and Thomas Luckmann., Review: The Social Construction of Reality: A Treatise in the Sociology of Knowledge., vol. 32, no. 1. Penguin Books. First published in the USA i, 1967.

[9] A. K. A. Dickson Adom, Akwasi Yeboah, "Constructivism Philosophical Paradigm: Implication for Research, Teaching, and Learning.," Glob. Arts Humanit. Soc. Sci., vol. 4, no. 10, p. 2016, 2016.

[10] O. Baldil, "Identity Formation in Postmodern Consumption Cultures: An Example of Rocker Subcultures," Int. J. Media Cult. Lit., vol. 2016, no. 3, pp. 87-108, 2016. 